This document is confidential and is proprietary to the American Chemical Society and its authors. Do not copy or disclose without written permission. If you have received this item in error, notify the sender and delete all copies.

\title{
Occurrence and behavior of macrolide antibiotics in municipal wastewater treatment: Possible importance of metabolites, synthesis by-products and transformation products
}

\begin{tabular}{|r|l|}
\hline Journal: & Environmental Science \& Technology \\
\hline Manuscript ID & es-2019-01420u.R1 \\
\hline Manuscript Type: & Article \\
\hline Author: & $\mathrm{n}$ /a \\
\hline Complete List of Authors: & $\begin{array}{l}\text { Senta, Ivan; Ruder Boskovic Institute, Division for Marine and } \\
\text { Environmental Research } \\
\text { Kostanjevecki, Petra; Ruder Boskovic Institute, Division for Marine and } \\
\text { Environmental Reseach } \\
\text { Krizman-Matasic, Ivona; Ruder Boskovic Institute, Division for Marine } \\
\text { and Environmental Research } \\
\text { Terzic, Senka; Ruder Boskovic Institute, Division for Marine and } \\
\text { Environmental Research } \\
\text { Ahel, Marijan; Ruder Boskovic Institute, Division for Marine and } \\
\text { Environmental Research }\end{array}$ \\
\hline
\end{tabular}

\section{SCHOLARONE Manuscripts}


1 Occurrence and behavior of macrolide antibiotics in municipal wastewater treatment:

2 Possible importance of metabolites, synthesis by-products and transformation products

$4 \quad$ Ivan Senta*, Petra Kostanjevecki, Ivona Krizman-Matasic, Senka Terzic**, Marijan Ahel 5

6 Division for Marine and Environmental Research, Rudjer Boskovic Institute, Bijenicka c. 54, 710000 Zagreb, Croatia

8

9

10

11

AUTHOR INFORMATION:

*Corresponding author: Ivan Senta (isenta@irb.hr)

14

**Corresponding author: Senka Terzic (terzic@irb.hr)

ORCID ID: 0000-0001-9351-3355 
17

18

19

20

21

22

\section{Abstract}

A one-year study on the occurrence and fate of macrolide antibiotics and their metabolites, synthesis by-products and transformation products (TPs) was performed in the wastewater treatment plant of the city of Zagreb (Croatia). The target compounds were found in all analyzed influent and effluent samples, with the total concentrations of azithromycin-, clarithromycin- and erythromycin-related compounds reaching up to 25,12 and $0.25 \mu \mathrm{g} / \mathrm{L}$, respectively. The most prominent individual constituents were the parent macrolides azithromycin and clarithromycin. However, a substantial contribution of their derivatives, formed by deglycolysation and microbial phosphorylation, was also detected. In addition, widespread presence of several linearized non-target TPs was confirmed for the first time in real wastewater samples by suspect screening analysis. Complex characterization of macrolide-derived compounds enabled decoupling of industrial and therapeutic sources from the insitu transformations. Due to the high inputs, incomplete removal and/or formation of several TPs during the conventional wastewater treatment, the average mass load of azithromycin-related compounds in secondary effluents exceeded $3.0 \mathrm{~g} /$ day/1000 inhabitants. This is the first study to reveal the importance of metabolites, by-products and TPs for the overall mass balance of macrolide antibiotics in urban wastewater systems.

Keywords: azithromycin, erythromycin, clarithromycin, intermediates, metabolites, transformation products 

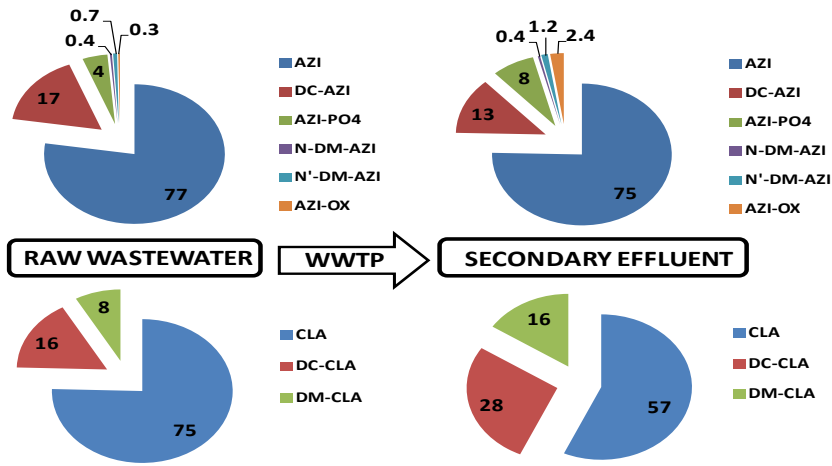

- CLA -DC-CLA DM-CLA

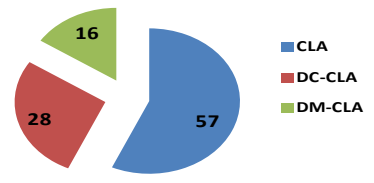

38 


\section{Introduction}

Antibiotics are widespread in the environment and represent one of the most extensively studied classes of emerging organic contaminants of pharmaceutical origin. Continuous exposure to antibiotics in the environment can cause different negative effects on non-target species, ${ }^{1}$ however a special concern has been raised regarding possible contribution of antibiotic residues to the development and proliferation of the resistant bacteria, which is one of the major global threats to human health in the near future. ${ }^{2}$ The ubiquitous occurrence of antibiotics in different environmental compartments has been confirmed in numerous studies in the last 20 years. ${ }^{3-6}$ Most of these studies pointed out urban wastewater as the major global source of antibiotics in the environment. Due to the incomplete removal of many classes of antibiotics during conventional and/or advanced wastewater treatment, ${ }^{7-11}$ significant quantities of antibiotic residues are continuously released into the receiving ambient waters and soil environments. However, most of the studies published so far were focused only on parent antibiotics, ${ }^{12}$ or, at best, included some major metabolites. ${ }^{4,5,13}$ On the other hand, the literature on the occurrence of transformation products (TPs) and synthesis byproducts in the aquatic environment is very scarce ${ }^{14-17}$ and their contribution to the overall mass balance of antibiotic-derived compounds remains largely unknown.

Among several classes of recalcitrant antibiotics, macrolides recently came under special scrutiny. Their main representatives - erythromycin (ERY), clarithromycin (CLA) and azithromycin (AZI) - have been included in the EU Watch List of potentially hazardous compounds for the aquatic environment. ${ }^{18}$ Widespread occurrence of macrolide antibiotics in urban wastewater, as well as their incomplete removal during wastewater treatment, has been frequently reported. ${ }^{5,19,20}$ Negative removal rates, observed in some of the studies, ${ }^{13,21}$ indicated possible significance of metabolites and/or TPs to the overall mass loads of macrolides in urban wastewater. Moreover, it was shown that the transformation processes in the environment, including both biotic ${ }^{22-25}$ and abiotic degradation ${ }^{26-29}$ can lead to formation of number of TPs, whose ecotoxicological properties are 
largely unknown. Several TPs of macrolide antibiotics, including those formed by opening macrolide ring, were recently found to be generated during microalgae wastewater treatment..$^{25}$ In our earlier study, novel TPs of AZI and roxythromycin (ROX), formed by microbial phosphorylation, were identified in wastewater effluent of a membrane bioreactor, ${ }^{30}$ while a recent study on aerobic biodegradation of AZI, CLA and ERY revealed a number of previously unreported, novel TPs and allowed proposing a general transformation pathways scheme for AZI. ${ }^{31}$ In addition, non-target analysis of freshwater sediments polluted by pharmaceutical industry effluent indicated the importance of intermediates in AZI synthesis. ${ }^{32}$ In order to address the complexity of macrolidederived compounds, we recently developed a novel quantitative analytical method, comprising parent macrolide antibiotics, their major human metabolites and TPs, as well as by-products from AZI synthesis, in wastewater and river water samples. ${ }^{17}$ This preliminary study clearly demonstrated the possible importance of non-parent macrolide compounds in municipal wastewater and industrial effluents. The concentrations of several metabolites and/or TPs of AZI and CLA were detected in municipal wastewater in similar concentration ranges as the parent antibiotics, while wastewater effluents from pharmaceutical industry were characterized by elevated concentrations of byproducts from AZI synthesis. ${ }^{17}$

The aim of this work was to perform a detailed study on the occurrence and fate of macroliderelated compounds in the central wastewater treatment plant (WWTP) of the city of Zagreb, covering a period of one year and encompassing both raw wastewater (RW) and biologically treated wastewater (secondary effluent; SE). The relevance of the applied comprehensive approach, which for the first time included an extended range of AZI-, ERY- and CLA-related compounds, was not only to demonstrate the need to include non-parent compounds in the overall risk assessment, but also to provide the clues for decoupling different sources based on the composition of macrolide constituents in a typical urban wastewater facility receiving mixed domestic and industrial wastewater. 


\section{Experimental}

\subsection{Chemicals and materials}

93

94

The target analytes included: AZI, decladinosyl azithromycin (DC-AZI), phosphorylated azithromycin $\left(\mathrm{AZI}-\mathrm{PO}_{4}\right), \quad \mathrm{N}$-demethyl azithromycin (N-DM-AZI), $\quad \mathrm{N}^{\prime}$-demethyl azithromycin (N'-DM-AZI), azithromycin $\mathrm{N}$-oxide (AZI-OX), anhydro erythromycin (ERY- $\left.\mathrm{H}_{2} \mathrm{O}\right)$, erythromycin enol ether (ERY-EE), $N$-demethyl erythromycin (DM-ERY), erythromycin imino ether (ERY-IE), erythromycin oxime (ERYOX), CLA, N-demethyl clarithromycin (DM-CLA), decladinosyl clarithromycin (DC-CLA) and ROX. Deuterated azithromycin (AZI- $\left.d_{3}\right)$ and clarithromycin (CLA- $\left.d_{3}\right)$ were used as internal standards. The structures and abbreviations of the target analytes included in the quantitative analytical method are presented in Figure S1 in Supporting Information (SI). Their reference standards were purchased from Toronto Research Chemicals (Canada), with the exception of AZI, ERY-IE, ERY-OX and CLA, which were kindly supplied by Pliva (Zagreb, Croatia), ROX, which was acquired from Sigma-Aldrich (Germany), and $\mathrm{AZI-PO}$, which was prepared in our laboratory by microbial transformation of AZI (details can be found in Senta et al., 2017). ${ }^{17}$

HPLC grade methanol $(\mathrm{MeOH})$ and acetonitrile $(\mathrm{ACN})$ were purchased from BDH Prolabo (UK) and ACS grade formic acid from Sigma-Aldrich. Elix-Milli-Q system (Millipore, USA) was used for the production of ultrapure water. Solid-phase extraction (SPE) cartridges Oasis HLB (200 mg/6 mL) and Strata SAX (100 mg/3 mL), were obtained from Waters (USA) and Phenomenex (USA), respectively, whereas glass-fiber filters (GF/D) were delivered by Whatman (UK). HPLC column ACE C18 PFP (150 × $3 \mathrm{~mm} ; 3 \mu \mathrm{m}$ ) was purchased from Advanced Chromatography Technologies (UK), whereas UPLC column Acquity BEH $C_{18}(50 \mathrm{~mm} \times 2.1 \mathrm{~mm} ; 1.7 \mu \mathrm{m})$ was purchased from Waters.

\subsection{Selection of the target compounds}


114 Our study was focused on three most prominent macrolide antibiotics - AZI, ERY and CLA, which were 115 recently included in the EU Watch list of potential surface water pollutants. ${ }^{18}$ Moreover, these substances account for almost entire consumption of macrolide antibiotics in Croatia. The macrolide consumption in 2014, expressed in defined daily doses (DDD) per 1000 inhabitants was $1.6,0.9$ and $<0.2$ for AZI, CLA and ERY, respectively. ${ }^{33}$ In addition, several other macrolide compounds related to AZI, ERY and CLA (Figure S1) were also included in quantitative analyses. These additional macrolidederived compounds can be classified into three categories as production intermediates and/or byproducts, human metabolites, and transformation products (TPs), predominately formed in wastewater itself.

It should be noted that parent ERY is very unstable at $\mathrm{pH} \leq 7$ and converts rapidly to $E R Y-\mathrm{H}_{2} \mathrm{O}$, its main metabolite and TP. ${ }^{34}$ This conversion is especially efficient at low $\mathrm{pH}$, such as in stomach of the patients treated with this antibiotic. ${ }^{35}$ This conversion also occurs in the environment, as well as during the sample preparation and analysis and, therefore, most of the methods for determination of ERY in environmental samples include ERY- $\mathrm{H}_{2} \mathrm{O}$ rather than parent ERY. ${ }^{13,19-21,34}$ In addition to ERY$\mathrm{H}_{2} \mathrm{O}$, the present study included ERY-EE, which was shown to be TP formed during biodegradation, ${ }^{22}$ as well as DM-ERY, which can be either metabolite formed by demethylation in the liver ${ }^{36}$ or microbial TP. ${ }^{31}$

Special attention was given to AZI, a semi-synthetic macrolide antibiotic produced from ERY. AZI was discovered in Croatia almost 40 years ago and has been manufactured in large quantities in the facilities located near the city of Zagreb for more than 30 years. Our study included all three intermediates in AZI synthesis - ERY-OX, ERY-IE and N-DM-AZI, as well as a suite of human metabolites and/or TPs (DC-AZI, N'-DM-AZI, AZI-PO ${ }_{4}$ and AZI-OX). DC-AZI and N'-DM-AZI are human metabolites of AZI, but they can also be formed as impurities during AZI synthesis and by in-situ

137 transformations in wastewater. On the other hand, AZI-PO $\mathrm{P}_{4}$ and $\mathrm{AZI}-\mathrm{OX}$ are classified as TPs, although

138 traces of AZI-OX can be formed during AZI synthesis as well. 
139 Two CLA-related compounds were included in the quantitative analytical method. DM-CLA is either 140 human metabolite of $\mathrm{CLA}^{37}$ or microbial TP, ${ }^{31}$ while DC-CLA, similar as DC-AZI, can be either byproduct of CLA synthesis or minor TP formed in wastewater itself. Unfortunately, due to the lack of a reference standard, major CLA metabolite, 14-hydroxy clarithromycin (CLA-OH), ${ }^{37}$ could be determined only semi-quantitatively.

Finally, another macrolide antibiotic, ROX, which is not included in the EU Watch list, was also analyzed, but only as a parent compound.

\subsection{Sampling}

24-h composite wastewater samples, including RW and SE, were collected in the central WWTP of the city of Zagreb (Croatia). All samples were time-proportional and were collected from 8 a.m. of the previous day to 8 a.m. of the sample collection day, with the sampling time interval of $15 \mathrm{~min}$. WWTP of the city of Zagreb is a full-scale mechanical-biological treatment plant which receives a combined municipal and industrial wastewater, including pharmaceutical industry effluents. It has designed capacity of 1.2 million population equivalents, but currently serves approximately 700,000 inhabitants. The average hydraulic load of raw wastewater is about $300,000 \mathrm{~m}^{3} /$ day and hydraulic retention time (HRT) is approximately $12 \mathrm{~h}$. Additional details about the WWTP can be found in SI (Table S1).

Collection of wastewater samples was performed using two sampling schemes. The main set of samples was collected over a period of approximately one-year (February to December 2017), by carrying out regular sampling on Monday and Wednesday of the same week, with a frequency once a month. The second scheme included collection of the wastewater samples during 7 consecutive days (Wednesday - Tuesday), covering a period of 1 week (from $22^{\text {nd }}$ to $28^{\text {th }}$ March 2017). In total, 29 RW and 29 SE samples were collected. 


\subsection{Sample treatment}

165

166

167

168

169

170

171

172

173

174

175

176

177

178

179

180

All wastewater samples collected within the one-year sampling interval were processed shortly after being brought back to the laboratory (typically 1-2 hours from sampling). Samples collected within the one-week sampling interval were frozen immediately after collection and processed later. All samples were treated according to the previously developed analytical procedure. ${ }^{17} \mathrm{~A}$ brief description of the applied analytical procedure is provided in SI.

In addition to wastewater samples, pills containing $500 \mathrm{mg}$ of either AZI or CLA were also analyzed. Each pill was first weighted and grained. A small aliquot was then dissolved in $\mathrm{MeOH}$ to prepare stock solutions containing $1 \mathrm{mg} / \mathrm{mL}$ of active ingredient (AZI or CLA). Stock solutions were then diluted with $100 \mathrm{mM}$ ammonium formate/MeOH $(1 / 1, v / v)$ for instrumental analysis.

\subsection{Instrumental analyses}

\subsubsection{Quantitative LC-MS/MS analysis}

Our previously developed analytical method, ${ }^{17}$ based on liquid chromatography coupled to tandem mass spectrometry (LC-MS/MS), was used for quantitative instrumental analysis. Target compounds were separated on ACE $C_{18}$ PFP HPLC column, using gradient elution with $0.1 \%$ formic acid in water $(v / v)$ and ACN as eluents. Detection and quantification were performed on a TSQ Quantum triple quadrupole instrument (Thermo Electron, USA), using multiple reaction monitoring (MRM) mode in positive polarity, with the two characteristic transitions selected for each target compound. First transition was used for quantification, whereas second transition, together with the ratio of the two transitions, was used for confirmation. The developed procedure allowed reliable determination of all target compounds included in the quantitative analytical method, with high accuracy $(\geq 75 \%)$ and 
repeatability (RSD $\leq 5 \%$ ) and low method quantification limits (MQL) (2-32 ng/L). All operational parameters, as well as detailed performance of the analytical method, can be found elsewhere. ${ }^{17}$ The method validation parameters for matrices included in this study are also given in SI (Table S2).

\subsubsection{Qualitative and semi-quantitative LC-MS analyses}

Additional, qualitative analyses of wastewater samples were performed by suspect screening of the extracts for a presence of the number of additional AZI and CLA TPs previously identified in model biotransformation experiments performed with the enriched sludge culture. ${ }^{31}$ Their structures can be found in SI (Figure S2 and S3). The screening was performed using ultrahigh-performance liquid chromatography (UHPLC) coupled to quadrupole-time-of-flight mass spectrometry (QToF MS), by applying the chromatographic and mass-spectrometric conditions given in Terzic et al. (2018). ${ }^{31}$ The identification of the additional TPs was made based on the accurate mass of protonated molecules and the retention time using samples from the model biotransformation experiments ${ }^{31}$ as qualitative reference standards. Furthermore, additional confirmation and approximative semi-quantitative determination of these additional TPs was performed by triple quadrupole LC-MS/MS system. Due to the lack of reference standards, their MRM transitions (Table S3) were selected manually, based on MS2 spectra recorded in above mentioned model biotransformation experiments, ${ }^{31}$ whereas the applied chromatographic conditions were identical to those applied for the quantitative MRM determinations of commercially available analytes. ${ }^{17}$

\section{Results and discussion}

\subsection{Occurrence of macrolide-derived compounds in raw wastewater and secondary effluent}


An overview of the occurrence of the target macrolide compounds in wastewater samples is presented in Table 1. Most of the analytes were found in all analyzed RW samples. The most prominent parent macrolide antibiotic was AZI, with concentrations ranging from 0.27 to $22.7 \mu \mathrm{g} / \mathrm{L}$ (average $5.8 \pm 5.3 \mu \mathrm{g} / \mathrm{L}$ ), which is generally an order of magnitude higher than the typical concentration ranges determined in municipal wastewater in similar studies ${ }^{4,9,38,39}$ Other AZI-related substances were also detected in all or in the majority of RW samples. The most abundant once were DC-AZI $(0.087-7.5 \mu \mathrm{g} / \mathrm{L})$ and AZI-PO $(0.049-1.2 \mu \mathrm{g} / \mathrm{L})$, whereas concentrations of other AZI-related compounds, especially specific markers of AZI-synthesis, were much lower ( $<100 \mathrm{ng} / \mathrm{L}$ ). Such distribution of AZI-related compounds was rather different from that found in the wastewater effluent receiving wastewater inputs from AZI-synthesis facility. ${ }^{17}$ The concentrations of CLA in wastewater of the city of Zagreb were significantly lower than the concentrations of AZI. In most of the RW samples CLA levels were below $1 \mu \mathrm{g} / \mathrm{L}$ (range 111-571 ng/L), with exception of two samples collected in April, when elevated concentrations (10 and $3.6 \mu \mathrm{g} / \mathrm{L}$ ) were determined. These concentration ranges are in line with most of the previous studies. $4,6,9,38,39$ Both CLA-related compounds included in quantitative target analyses (DC-CLA and DM-CLA) were also determined in all analyzed samples, but their concentrations were consistently lower than the concentrations of parent CLA. For ERY-related compounds the concentrations were even lower, indicating significantly lower consumption of ERY in human therapy. The concentrations of ERY- $\mathrm{H}_{2} \mathrm{O}$ and EEE, as the prevalent ERY-related compounds, were typically below $50 \mathrm{ng} / \mathrm{L}$ and $20 \mathrm{ng} / \mathrm{L}$, respectively, with only few exceptions observed in March. Moreover, only traces of possible ERY TPs, such as DM-ERY, were occasionally detected, but the concentrations were always below the MQL. The concentrations of ERY- $\mathrm{H}_{2} \mathrm{O}$ were either similar or lower than the concentrations determined in other studies. $., 19,20$ Finally, in our survey, ROX was not detected in any of the analyzed samples, which is in accordance with its very limited usage in Croatia, ${ }^{33}$ as well as with the previous data. ${ }^{5}$ In qualitative terms, our results are in accordance with the use of macrolide antibiotics in Croatia ( $A Z I>C L A>E R Y>R O X)$. 
233 It should be stressed that all compounds determined in RW were also found in SE, with similar 234 detection frequencies and concentration ranges. In fact, concentrations of some substances were often higher in SE than in RW samples, which is further discussed in Section 3.3.

Figure 1 shows the average relative contribution of each individual compound to the total loads of AZI- and CLA-related substances in RW and SE and clearly illustrates the importance of non-parent compounds to the mass balance of the target macrolides. Already in RW, the contribution of metabolites, by-products and TPs reached a significant percentage of approximately $25 \%$ for both macrolides. It is interesting to note that after secondary treatment the contribution of non-parent macrolides remained almost the same for AZI but significantly increased (44\%) for CLA. Along these lines, it should be stressed that the major human metabolite, CLA-OH, was not included in this calculation, due to the lack of a quantitative reference standard, however our semi-quantitative estimates indicate that inclusion of $\mathrm{CLA}-\mathrm{OH}$ would further shift the mass balance towards the predominance of non-parent CLA compounds. This is particularly important when we consider that $\mathrm{CLA}-\mathrm{OH}$ retains the antibiotic activity after the transformation from $\mathrm{CLA} .{ }^{37}$

\subsection{Mass loads and decoupling of possible sources of macrolides in RW}

249 Mass loads of the target compounds were calculated by multiplying their concentrations by the volume of wastewater passing daily through the WWTP. Mass loads of AZI- and CLA-related compounds in RW are presented in Figure 2 (one-year sampling interval) and Figure 3 (one-week sampling interval). It should be noted that in these Figures parent antibiotics are presented individually, whereas the mass loads of related substances (metabolites, by-products and TPs) are summed up. The individual mass loads of all major AZI- and CLA-related compounds determined during the one-year sampling interval are additionally presented in Figure $\mathrm{S} 4$ and $\mathrm{S} 5$ (SI), respectively. 
Figure 2 shows that the mass loads of parent AZI were markedly variable ( 88 to $6861 \mathrm{~g} /$ day), with several distinctive peaks throughout the year. The average value of $1861 \pm 1744 \mathrm{~g} / \mathrm{day}$ is an order of magnitude higher than the typical mass loads ( $121 \pm 64 \mathrm{~g} /$ day) determined in the investigated WWTP in our previous study. ${ }^{5}$ A rather similar one-year temporal pattern was also observed for DC-AZI, AZI$\mathrm{PO}_{4}$ and AZI-OX (Figure S4, $\mathrm{SI}$ ), but their mass loads were comparatively lower $(323 \pm 485,111 \pm 77$ and $8.2 \pm 9.7 \mathrm{~g} /$ day, respectively).

Substantial increase in the mass loads of AZI (15 times), compared to our previous study performed in $2009,{ }^{5}$ cannot be linked to the increased use of this antibiotic in human medicine. According to the official statistics, consumption of AZI in the last decade increased only about $30 \%^{33}$ and can be estimated at approximately $350 \mathrm{~g} /$ day for the city of Zagreb, which is 5 times lower than the average mass load determined in our study, even if we ignore metabolic transformation of AZI, which would make this difference even more pronounced. Moreover, if human consumption is supposed to be the main source of input of this antibiotic in wastewater, the observed extreme variability of AZI mass loads (over two orders of magnitude during a single year) would be highly unlikely. Furthermore, it is even more difficult to associate the variability of the mass loads of over one order of magnitude during a single week (Figure 3) with the therapeutic use of AZI. For example, our previous studies on opioid analgesics in the same WWTP indicated a rather small variability of therapeutic consumption during the week..$^{40}$ These findings suggest a direct disposal as the main source of input of AZI in the investigated WWTP during the peak concentrations. Having in mind that investigated WWTP receives mixed domestic and industrial wastewaters, possible source of the enhanced AZI mass loads might have been local pharmaceutical industry, which produces substantial amount of macrolide antibiotics, especially AZI. Since the facility for AZI synthesis is located outside of the city of Zagreb and does not discharge its wastewater to the sewer system of the city, this indicated that some other pharmaceutical industry processes, such as formulation and packing of macrolide active ingredients, represented the most likely additional source of AZI in the investigated WWTP. Moreover, it was 
concentrations of AZI synthesis intermediates (up to $5.7 \mathrm{mg} / \mathrm{L}$ ), ${ }^{17}$ whereas the concentrations of these compounds in the municipal wastewater samples of the city of Zagreb, analyzed in this study were rather low (N-DM AZI: <MQL-70 ng/L; ERY-OX: <MQL-12 ng/L; ERY-IE: <MQL). Disposal of unused medications directly into the sewer system as a possible alternative source of occasionally high loads of AZI does not seem very likely.

The mass loads of CLA in most of the RW samples were between 28 and $188 \mathrm{~g} /$ day, which is generally comparable with the previously reported data for this WWTP. ${ }^{5}$ However, much higher mass loads, 2798 and $1019 \mathrm{~g} /$ day, were determined in two samples collected in April. A very similar temporal pattern, with distinctive peak in April (416 and $284 \mathrm{~g} /$ day), was also observed for DC-CLA (Figure S5, SI). This highly irregular feature indicated the existence of an additional source of CLA during that short period. Otherwise, the mass loads of CLA were much less variable than the mass loads of AZI, both within the investigated one-year (Figure 2) and one-week sampling interval (Figure 3) and were in line with the mass loads which can be estimated from human therapeutic use. ${ }^{33}$ The exceptional stability of CLA levels in one-week survey (RSD 7\%) clearly indicated that the variability of human consumption within a week was less than $10 \%$ and, therefore, sudden changes must have been a consequence of an additional non-therapeutic input. Thus, the observed extreme increase of CLA mass loads (Figure 2), which was evidenced in April, was interpreted as an occasional release of CLA from the pharmaceutical facilities.

Mass loads of ERY $-\mathrm{H}_{2} \mathrm{O}\left(2.4-37 \mathrm{~g} /\right.$ day) were similar as in our previous study ${ }^{5}$ and most probably reflected a rather restricted human consumption of ERY in Croatia, ${ }^{33}$ although possible contribution from veterinary medicine cannot be excluded. The contribution of other ERY-related compounds to the total mass loads was even lower.

In order to estimate the possible contribution of non-parent macrolide compounds from formulation facilities, we analyzed AZI and CLA pills from the local manufacturer for the main impurities. Their mass fractions were calculated as percentages of the mass of the corresponding parent antibiotic in 
the pill. The results, presented in Table S4 (SI), show that several AZI- and CLA-related compounds determined in RW were also detected in the analyzed pills. In the RW samples characterized by largely enhanced concentrations of AZI and CLA, the contribution of impurities, such as N-DMA, N'DMA and AZI-OX, was typically lower than $1 \%$, which was rather close to the levels in the analyzed pills. However, the average percentages of N-DMA, N'-DMA and AOX in all other RW samples were $1.2 \%, 1.6 \%$ and $0.5 \%$, respectively, indicating a significant contribution of therapeutic consumption and/or formation in the sewer system after disposal. It should be stressed that the average percentages of DC-AZI and DC-CLA were rather high (17\% and 16\%, respectively), exceeding the percentages found in pills more than 100 times. Therefore, there is a strong indication that these decladinosyl derivatives originated primarily from an additional formation in the sewer. We assume that this hypoxic environment could harbor bacteria which contain enzymes capable of transforming macrolide antibiotics, as recently suggested in the study by Gonzalez-Gil et al. ${ }^{41}$ Along these lines, it should be stressed that characteristic phosphorylated TPs were not detected in the pills, while their contribution in RW reached an average of $8.8 \%$. Therefore, it seems that phosphorylated macrolides can be used as exclusive indicators of their microbial transformations in the wastewater itself. On the other hand, most of the remaining substances can have multiple sources, which makes their exclusive assignment to individual classes (metabolites, TPs and by-products) very difficult.

Seasonal trends of the mass loads of AZI and CLA-related compounds were also investigated, and the results are presented in Fig S6 A (SI). Although some differences were observed, they were not statistically significant, due to the high variability of the mass loads in the investigated period, caused by non-therapeutic sources, especially for AZI. However, if the mass loads of CLA determined in April were excluded, a clear seasonal trend, with the significantly lower loads (one-way ANOVA; $p<0.001$ ) during the summer was obtained for this compound (Fig S6 B, $\mathrm{SI}$ ), which is in line with the previous studies. ${ }^{42-44}$ This can be explained with the lower consumption of macrolide antibiotics, which are mostly used to treat respiratory infections, during summer months. This observation additionally 
consumption, with exception of the two samples collected in April, when direct disposal from pharmaceutical industry greatly surpassed the contribution from human consumption.

\subsection{Behavior of macrolide-derived compounds during activated sludge treatment}

As already pointed out in Section 3.1., the concentrations of several macrolide substances were similar or even higher in SE than in RW, indicating their incomplete removal during conventional wastewater treatment. However, it should be noted that HRT in the investigated WWTP is rather short (12 h), which may hamper the accurate determination of the removal efficiency when 24-hours samples are collected, especially in the case of frequent pulse discharges from pharmaceutical facilities, causing high diurnal variability of the target compounds in wastewater. Therefore, removal rates calculated from 24-hour composite samples collected on the same date were found to be inaccurate and highly variable. Nevertheless, although removal rates of the individual target compounds could not be accurately determined for the samples collected in the one-year sampling interval, figures showing their mass loads in RW and SE (Figure S4 and S5, SI) can provide valuable additional information on their behavior during conventional wastewater treatment at a larger timescale, covering different seasons.

To obtain more robust and reliable results, the removal efficiencies of the target macrolides were assessed based on the weekly mass balance exercise carried out during seven consecutive days. The results on the weekly mass loads in RW and SE and the removal efficiencies for the major macrolidederived compounds are presented in Table 2. This approach successfully compensated the inconsistencies associated with the industrial pulse of AZI from $24^{\text {th }}$ March. Table 2 shows that CLA was the only major macrolide with elimination above $50 \%$. Removal efficiency for this substance was very similar as in our previous study in the same WWTP 5 and in line with the findings in the one-year sampling interval. Partial removal was also obtained for DM-CLA, as well as for ERY- $\mathrm{H}_{2} \mathrm{O}$, which removal rate was slightly higher than in the previous study, but still below $40 \%$. On the other hand, 
virtually no removal was observed for $\mathrm{AZI}, \mathrm{AZI}-\mathrm{PO}_{4}$ and $\mathrm{DC}-\mathrm{CLA}$. Low removal of parent $\mathrm{AZI}$ in the investigated WWTP has been already reported in the literature..$^{5}$ On the other hand, negative removal rates were obtained for DC-AZI and N'-DM-AZI, whose mass loads were approximately 2.5 times higher in SE than in RW during the one-week sampling interval. This was even more pronounced for AZI-OX, which showed an order of magnitude higher mass loads in SE than in RW. Rather similar features for AZI-OX and N'-DM-AZI were also observed during the one-year sampling interval (Figure S4, SI). This suggested possible formation of these TPs during conventional wastewater treatment. On the other hand, results for DC-AZI were less consistent. In fact, in some cases, mostly during the pulse discharges from pharmaceutical facilities, higher mass loads of DC-AZI were determined in RW than in SE. As pointed out above, DC-AZI can have multiple sources, including AZI instability in pharmaceutical formulations, human metabolism and additional formation in the sewer system. A high percentage of DC-AZI in RW (17\%) indicated the prevalence of the last two mechanisms. Our previous aerobic biodegradation study ${ }^{31}$ suggested the loss of cladinose as an important step in the overall transformation pathway, but did not show any accumulation of DC-AZI as a major stable TP. This is consistent with the observations on DC-AZI levels in SE over the one-year cycle. Since kinetics of both abiotic and biotic transformations are expected to depend on environmental factors such as water temperature, $\mathrm{pH}$ and microbial community composition, further studies are needed to address this issue in more detail.

It is important to point out that, as a combined result of high inputs in RW and low removal during conventional wastewater treatment, substantial amount (up to $8800 \mathrm{~g} /$ day) of AZI-related compounds is discharged from the investigated WWTP into the receiving surface water. Due to the significant contribution of industrial inputs, the population normalized average mass load of AZIrelated compounds was $3.3 \mathrm{~g} /$ day $/ 1000$ inhabitants, which is significantly higher than the average mass loads of macrolide antibiotics in municipal WWTPs reported in some previous studies ${ }^{19,44}$ and the mass loads which can be estimated from the consumption data $(0.48 \mathrm{~g} /$ day $/ 1000$ inhabitants $){ }^{33}$ 
Finally, it should be noted that this study was focused only on the dissolved phase. For the complete mass balance study in the wastewater treatment, the analysis of macrolide compounds incorporated into the suspended particles should be performed as well. This might be especially important for AZIrelated compounds, due to the strong sorption properties of parent AZI. ${ }^{5}$

\subsection{Screening for additional transformation products}

In contrast to synthesis by-products and human metabolites, the term transformation product in this work was meant for the macrolide products formed primarily in the wastewater itself. Wastewater extracts prepared for the target analyses were also screened for additional AZI- and CLA-related compounds using high resolution MS in combination with MRM (MS/MS) confirmation. The emphasis was on TPs which were previously identified in model aerobic biotransformation experiments using enriched activated sludge culture from the same WWTP. ${ }^{31}$ For structural assignments see SI (Fig S2 and S3). It should be pointed out that pure reference standards of these compounds were not available, which prevented obtaining fully quantitative results. Nevertheless, the media from biotransformation experiments described in Terzic et al. (2018) ${ }^{31}$ were applied as qualitative standards, providing link to structural information, as well as to retention time data for the additional TPs. The overview of the TPs encompassed by this screening is presented in Table 3 . The accurate mass data for all detectable TPs were within the tolerance limits of $5 \mathrm{mDa}$, while additional confirmation was achieved by MRM analysis, using two characteristic transitions for each TP (Table S3, SI). The most abundant additional AZI TPs were those which included macrolide ring opening and/or deglycosylation (loss of sugar moieties; TP 767, TP 610, TP 452, TP 592), followed by oxidative transformations of the linearized macrolide TPs (TP 376, TP 374bc, TP 358).

Semi-quantitative estimates, assuming equal molar responses for all AZI-related compounds in QToF analysis, indicated that the concentrations of individual TPs were always less than $5 \%$ of AZI concentration (average about 1\%). However, their relative contribution was significantly enhanced in 
408 SE as compared to RW. The increase during secondary treatment varied from 3 for TP 394 to 2000 409 times for TP 376a (Figure S7, SI), supporting the hypothesis that they can be regarded as highly specific markers of aerobic transformations, although their contribution to the overall mass balance during secondary treatment was rather low.

Regarding additional TPs of CLA, three prominent TPs were identified. The most abundant one was $\mathrm{CLA}-\mathrm{OH}$, which represented approximately $50 \%$ of the parent CLA levels (obtained by assuming equal responses of CLA-OH and CLA) and very probably contributed significantly to the CLA mass balance. The preliminary evidence does not indicate its formation during secondary treatment, however this compound remains highly relevant for the overall risk assessment, because it fully retains the antibiotic activity of CLA. In contrast to CLA-OH, concentration of phosphorylated CLA was about 5.9 times higher in SE than in RW, indicating net formation during secondary treatment. The similar SE/RW ratio was observed for TP 766, which is formed by opening of the CLA macrolide ring, indicating similarity with transformation pattern of AZI.

421 Collectively, in the present study we demonstrated for the first time the need for a more comprehensive approach when addressing the issue of macrolide antibiotics as contaminants of emerging concern. Complex characterization of macrolide-derived compounds, including determination of synthesis by-products, human metabolites and TPs, provides a basis for decoupling of industrial and therapeutic sources from the in-situ transformations. The overall removal of macrolide-derived compounds during the conventional wastewater treatment was shown to be

427 rather low, which warrants a careful ecotoxicological evaluation of their complex mixtures present in municipal sewage effluents and calls urgently for a more detailed understanding of their behavior and fate in the aquatic environment. Finally, the results obtained in this study could also contribute 


\section{Acknowledgment}

This study was financially supported by Croatian Science Foundation (project COMPASS; grant number IP-2014-09-7031). We are thankful to the staff of the Central WWTP of the city of Zagreb for their cooperation in wastewater collection. The technical assistance of Nenad Muhin is also highly appreciated.

\section{ASSOCIATED CONTENT}

\section{Supporting Information}

Structures and abbreviations of target compounds; Key characteristics of the investigated WWTP; Brief description of analytical procedure and method validation data; MRM transitions used for the analyses of additional AZI and CLA TPs; Structures of additional AZI and CLA TPs included in suspect screening; Annual variability of daily mass loads of target compounds in RW and SE; Seasonal trends of AZI and CLA in RW; Ratios of additional AZI and CLA TPs in SE and RW samples. This information is available free of charge via the Internet at http://pubs.acs.org.

\section{References}

(1) Bielen, A.; Šimatović, A.; Kosić-Vukšić, J.; Senta, I.; Ahel, M.; Babić, S.; Jurina, T.; González Plaza, J.J.; Milaković, M.; Udiković-Kolić, N. Negative environmental impacts of antibiotic-contaminated effluents from pharmaceutical industries. Water Res. 2017, 126, 79-87.

(2) Laxminarayan, R.; Duse, A.; Wattal, C.; Zaidi, A.K.M.; Wertheim, H.F.L.; Sumpradit, N.; Vlieghe, E.; Hara, G.L; Gould, I.M.; Goossens, H.; Greko, C.; So, A.D.; Bigdeli, M.; Tomson, G.; Woodhouse, W.; Ombaka, E.; Peralta, A.Q.; Qamar, F.N.; Mir, F.; Kariuki, S.; Bhutta, Z.A.; Coates, A.; Bergstrom, R.; Wright, G.D.; Brown, E.D.; Cars, O. Antibiotic resistance - the need for global solutions. Lancet 
Infect. Dis. 2013, 13, 1057-1098.

455

(3) Kümmerer, K. Antibiotics in the aquatic environment - a review - part I. Chemosphere 2009, 75, 417-434.

(4) Rodríguez-Mozaz, S.; Chamorro, S.; Marti, E.; Huerta, B.; Gros, M.; Sànchez-Melsió, A.; Borrego,

C.M.; Barceló, D.; Balcázar, J.L. Occurrence of antibiotics and antibiotic resistance genes in hospital and urban wastewaters and their impact on the receiving river. Water Res. 2015, 69, 234-242.

(5) Senta, I.; Terzic, S.; Ahel, M. Occurrence and fate of dissolved and particulate antimicrobials in municipal wastewater treatment. Water Res. 2013, 47, 705-714.

(6) Zuccato, E.; Castiglioni, S.; Bagnati, R.; Melis, M.; Fanelli, R. Source, occurrence and fate of antibiotics in the Italian aquatic environment. J. Hazard. Mater. 2010, 179, 1042-1048.

(7) Le-Minh, N.; Khan, S.J.; Drewes, J.E.; Stuetz, R.M. Fate of antibiotics during municipal water recycling treatment processes. Water Res. 2010, 44, 4295-4323.

(8) Marx, C.; Günther, N.; Schubert, S.; Oertel, R.; Ahnert, M.; Krebs, P.; Kuehn, V. Mass flow of antibiotics in a wastewater treatment plant focusing on removal variations due to operational parameters. Sci. Total Environ. 2015, 538, 779-788.

(9) Michael, I.; Rizzo, L.; McArdell, C.S.; Manaia, C.M.; Merlin, C.; Schwartz, T.; Dagot, C.; FattaKassinos, D. Urban wastewater treatment plants as hotspots for the release of antibiotics in the environment: A review. Water Res. 2013, 47, 957-995. antimicrobials using advanced wastewater treatment. J. Hazard. Mater. 2011, 192, 319-328. wastewater treatment : Implications for environmental discharge and wastewater recycling. Water Res. 2007, 41, 4164-4176. 
477 (12) Seifrtová, M.; Nováková, L.; Lino, C.; Pena, A.; Solich, P. An overview of analytical methodologies 478 for the determination of antibiotics in environmental waters. Anal. Chim. Acta 2009, 649, 158-179.

479 (13) Göbel, A.; McArdell, C.S.; Joss, A.; Siegrist, H.; Giger, W. Fate of sulfonamides, macrolides, and 480 trimethoprim in different wastewater treatment technologies. Sci. Total Environ. 2007, 372, 361481371.

482

483

484

486

487

488

489

490

491

492

493

494

495

496

497

498

499

(14) Pérez-Parada, A.; Agüera, A.; Gómez-Ramos, M.D.; García-Reyes, J.F.; Heinzen, H.; FernándezAlba, A.R. Behavior of amoxicillin in wastewater and river water: identification of its main transformation products by liquid chromatography/electrospray quadrupole time-of-flight mass spectrometry, Rapid Commun. Mass Spectrom. 2011, 25, 731-742.

(15) Hirte, K.; Seiwert, B.; Schüürmann, G.; Reemtsma, T. New hydrolysis products of the beta-lactam antibiotic amoxicillin, their pH-dependent formation and search in municipal wastewater, Water Res. $2016,88,880-888$.

(16) Ibañez, M.; Borova, V.; Boix, C.; Aalizadeh, R.; Bade, R.; Thomaidis, N.S.; Hernández, F. UHPLCQTOF MS screening of pharmaceuticals and their metabolites in treated wastewater samples from Athens, J. Hazard. Mater. 2017, 323, 26-35.

(17) Senta, I.; Krizman-Matasic, I.; Terzic, S.; Ahel, M. Comprehensive determination of macrolide antibiotics, their synthesis intermediates and transformation products in wastewater effluents and ambient waters by liquid chromatography-tandem mass spectrometry. J. Chromatogr. A 2017, 1509, 60-68.

(18) Commission Implementing Decision (EU) 2015/495 Establishing a Watch List of Substances for Union-Wide Monitoring in the Field of Water Policy Pursuant to Directive 2008/105/EC of the European Parliament and of the Council. https://eur-lex.europa.eu/legalcontent/EN/TXT/PDF/?uri=CELEX:32015D0495\&from=EN (accessed Jan 25, 2019). 
500 (19) Lin, H.; Li, H.; Chen, L.; Li, L.; Yin, L.; Lee, H.; Yang, Z. Mass loading and emission of thirty-seven 501 pharmaceuticals in a typical municipal wastewater treatment plant in Hunan Province, Southern 502 China. Ecotoxicol. Environ. Safe. 2018, 147, 530-536.

503 (20) Xu, W.; Zhang, G.; Li, X.; Zou, S.; Li, P.; Hu, Z.; Li, J. Occurrence and elimination of antibiotics at 504 four sewage treatment plants in the Pearl River Delta (PRD), South China. Water Res. 2007, 41, 45265054534.

506

507

508

509

510

511

512

513

514

(21) Zhang, X.; Zhao, H.; Du, J.; Qu, Y.; Shen, C.; Tan, F.; Chen, J.; Quan, X. Occurrence, removal, and risk assessment of antibiotics in 12 wastewater treatment plants from Dalian, China. Environ. Sci. Pollut. Res. 2017, 24, 16478-16487.

(22) Kwon, J.-W. Environmental impact assessment of veterinary drug on fish aquaculture for food safety. Drug Test. Anal. 2016, 8, 556-564.

(23) Topp, E.; Renaud, J.; Sumarah, M.; Sabourin, L. Reduced persistence of the macrolide antibiotics erythromycin, clarithromycin and azithromycin in agricultural soil following several years of exposure in the field. Sci. Total Environ. 2016, 562, 136-144.

(24) Maier, M.L.V.; Tjeerdema, R.S. Azithromycin sorption and biodegradation in a simulated California river system. Chemosphere 2018, 190, 471-480.

(25) Jaén-Gil, A.; Hom-Diaz, A.; Llorca, M.; Vicent, T.; Blánquez, P.; Barceló, D.; Rodríguez-Mozaz, S. An automated on-line turbulent flow liquid-chromatography technology coupled to a high resolution mass spectrometer LTQ-Orbitrap for suspect screening of antibiotic transformation products during microalgae wastewater treatment, J. Chromatogr. A 2018, 1568, 57-68.

(26) Batchu, S.R.; Panditi, V.R.; O'Shea, K.E.; Gardinali, P.R. Photodegradation of antibiotics under simulated solar radiation: Implications for their environmental fate. Sci. Total Environ. 2014, 470$471,299-310$. 
523 (27) Calza, P.; Marchisio, S.; Medana, C.; Baiocchi, C. Fate of antibacterial spiramycin in river waters.

524 Anal. Bioanal. Chem. 2010, 396, 1539-1550.

525 (28) Tong, L.; Eichhorn, P.; Pérez, S.; Wang, Y.; Barceló, D. Photodegradation of azithromycin in 526 various aqueous systems under simulated and natural solar radiation: Kinetics and identification of 527 photoproducts. Chemosphere 2011, 83, 340-348.

528

529

530

531

532

533

534

535

536

537

538

539

540

541

542

543

544

545

(29) Gozlan, I.; Koren, I.; Avisar, D. Identification, mechanisms and kinetics of macrolide degradation product formation under controlled environmental conditions. J. Environ. Anal. Chem. 2016, 3, 1000171

(30) Terzic, S.; Senta, I.; Matosic, M.; Ahel, M. Identification of biotransformation products of macrolide and fluoroquinolone antimicrobials in membrane bioreactor treatment by ultrahighperformance liquid chromatography/quadrupole time-of-flight mass spectrometry. Anal. Bioanal. Chem. 2011, 401, 353-363.

(31) Terzic, S.; Udikovic-Kolic, N.; Jurina, T.; Krizman-Matasic, I.; Senta, I.; Mihaljevic, I.; Loncar, J.; Smital, T.; Ahel, M. Biotransformation of macrolide antibiotics using enriched activated sludge culture: Kinetics, transformation routes and ecotoxicological evaluation. J. Hazard. Mater. 2018, 349, 143-152.

(32) Terzic, S.; Ahel, M. Nontarget analysis of polar contaminants in freshwater sediments influenced by pharmaceutical industry using ultra-high-pressure liquid chromatography-quadrupole time-offlight mass spectrometry. Environ. Pollut. 2011, 159, 557-566.

(33) Daus-Šebeđak, D.; Vrcić Keglević, M. Ten-year trends in the utilization of antibiotics in Croatia on the basis of routinely collected data (Desetogodišnji trendovi potrošnje antibiotika u Republici Hrvatskoj: studija utemeljena na rutinski prikupljenim podatcima), Acta Med. Croatica 2017, 71, 263271. (in Croatian) 
546 (34) Senta, I.; Terzić, S.; Ahel, M. Simultaneous Determination of Sulfonamides, Fluoroquinolones, 547 Macrolides and Trimethoprim in Wastewater and River Water by LC-Tandem-MS. Chromatographia $548 \quad 2008,68,747-758$.

549 (35) Kavi, J.; Webberley, J.M.; Andrews, J.M.; Wise, R. A comparison of the pharmacokinetics and 550 tissue penetration of spiramycin and erythromycin, J. Antimicrob. Chemoth. 1988, 22, Suppl. B, 105551110.

552 (36) Mao, J.C.-H.; Tardrew, P.L. Demethylation of erythromycins by rabbit tissues in vitro, Biochem. Pharmacol. 1965, 14, 1049-1058.

(37) Rodvold, K.A. Clinical Pharmacokinetics of Clarithromycin. Clin. Pharmacokinet. 1999, 37, 385555 398.

(38) Golovko, O.; Kumar, V.; Fedorova, G.; Randak, T.; Grabic, R. Seasonal changes in antibiotics,

557 558

559 antidepressants/psychiatric drugs, antihistamines and lipid regulators in a wastewater treatment plant. Chemosphere 2014, 111, 418-426.

(39) Ben, W.; Zhu, B.; Yuan, X.; Zhang, Y.; Yang, M.; Qiang, Z. Occurrence, removal and risk of organic micropollutants in wastewater treatment plants across China: Comparison of wastewater treatment processes. Water Res. 2018, 130, 38-46.

(40) Krizman-Matasic, I.; Senta, I.; Kostanjevecki, P.; Ahel, M.; Terzic, S. Long-term monitoring of drug consumption patterns in a large-sized European city using wastewater-based epidemiology: Comparison of two sampling schemes for the assessment of multiannual trends. Sci. Total. Environ. $2019,647,474-485$.

(41) Gonzalez-Gil, L.; Krah, D.; Ghattas, A.-K.; Carballa, M.; Wick, A.; Helmholz, L.; Lema, J.M.; Ternes, T.A. Biotransformation of organic micropollutants by anaerobic sludge enzymes. Water Res. 2019, $152,202-214$. 
569 (42) McArdell, C.S.; Molnar, E.; Suter, M.J.-F.; Giger, W. Occurrence and Fate of Macrolide Antibiotics

570 in Wastewater Treatment Plants and in the Glatt Valley Watershed, Switzerland. Environ. Sci.

571 Technol. 2003, 37, 5479-5486.

572 (43) Valcárcel, Y.; Alonso, S.G.; Rodríguez-Gil, J.L.; Castaño, A.; Montero, J.C.; Criado-Alvarez, J.J.;

573 Mirón, I.J.; Catalá, M. Seasonal variation of pharmaceutically active compounds in surface (Tagus

574 River) and tap water (Central Spain). Environ. Sci. Pollut. Res. 2013, 20, 1396-1412.

575 (44) Castiglioni, S.; Bagnati, R.; Fanelli, R.; Pomati, F.; Calamari, D.; Zuccato, E. Removal of 576 pharmaceuticals in sewage treatment plants in Italy. Environ. Sci. Technol. 2006, 40, 357-363. 


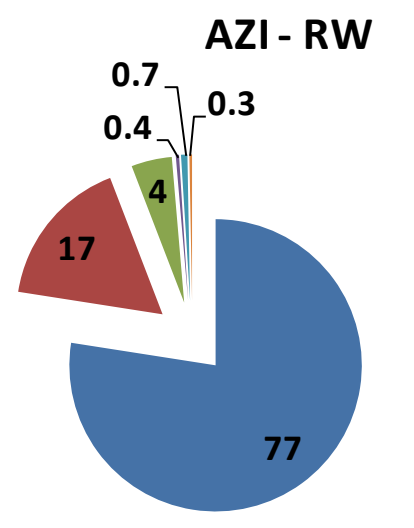

CLA - RW

578

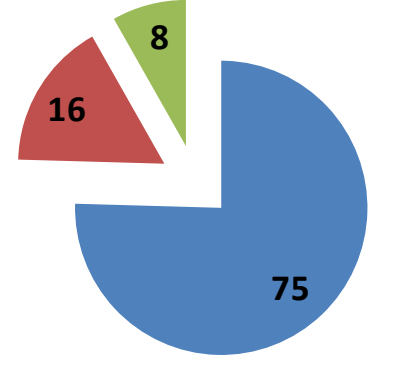

\section{AZI}

DC-AZI

AZI-PO4

N-DM-AZI

N'-DM-AZI

AZI-OX

- CLA

DC-CLA

DM-CLA

Figure 1. Average relative contribution of individual compounds to the total loads of azithromycin (AZI) and clarithromycin (CLA) in raw wastewater (RW) and secondary effluent (SE) of the wastewater treatment plant of the city of Zagreb. 

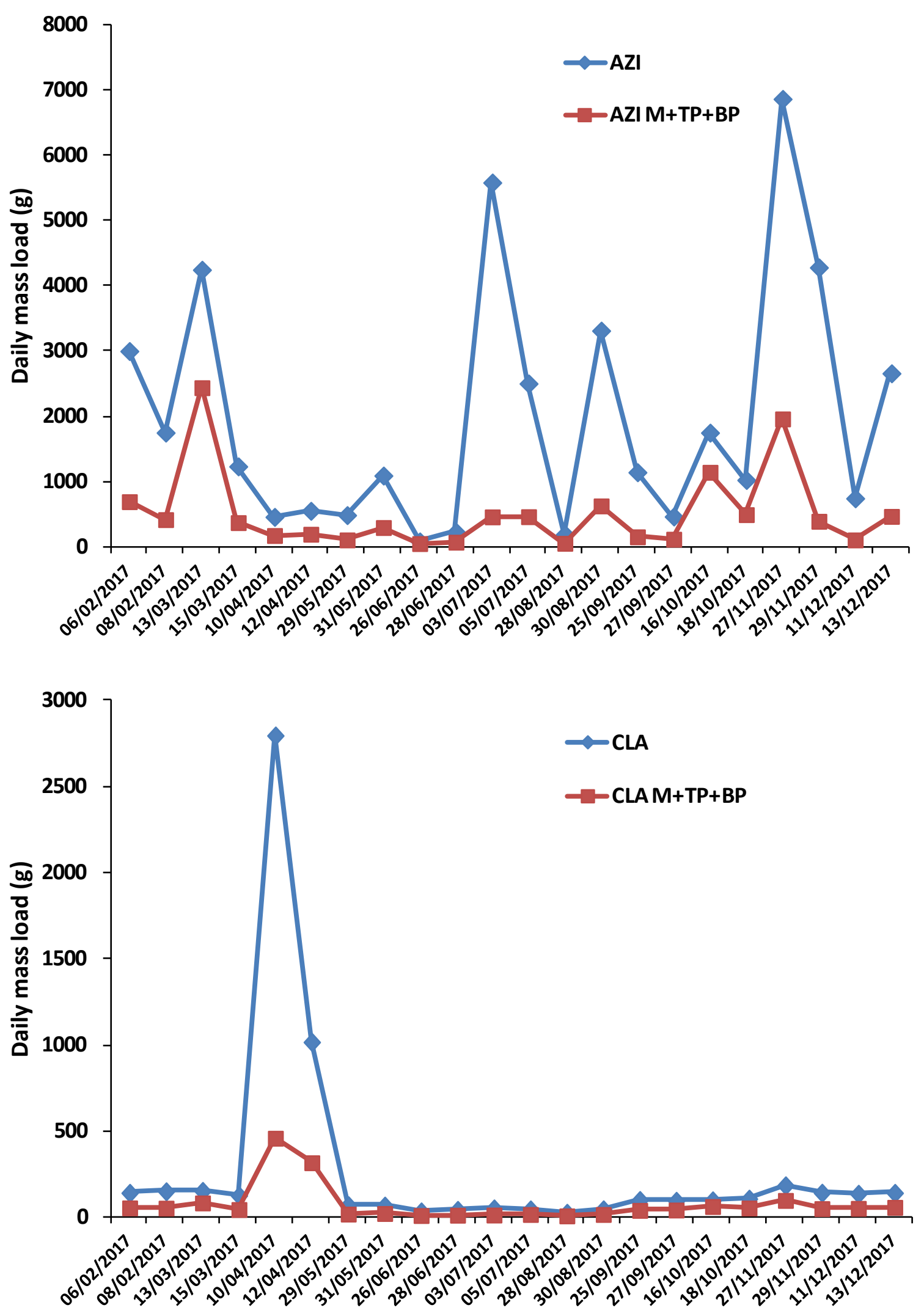

Figure 2. Daily mass loads of azithromycin (AZI) and clarithromycin (CLA), along with the sum of their metabolites (M), transformation products (TP) and by-products (BP), to the wastewater treatment plant of the city of Zagreb during 2017 (one-year sampling interval). 

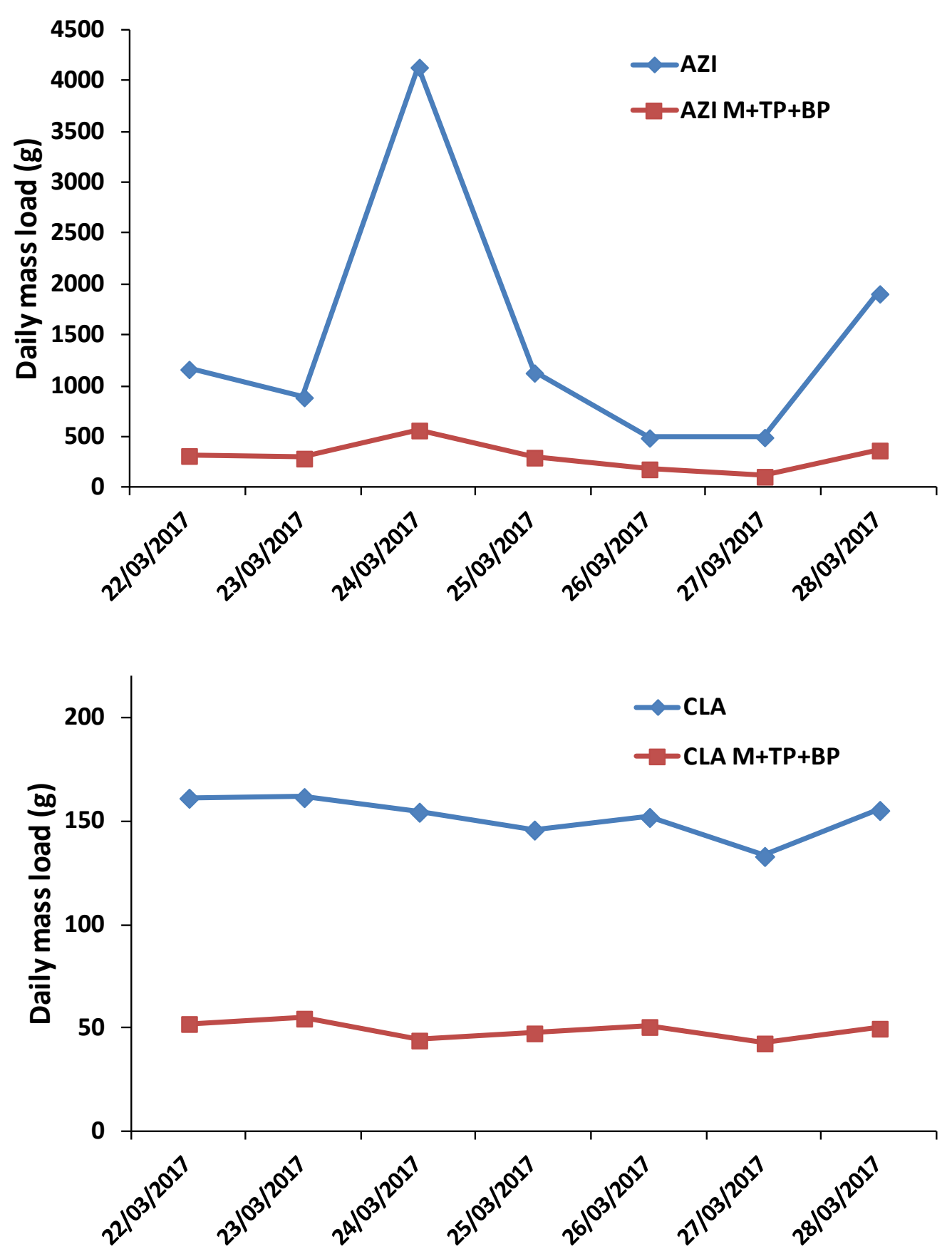

589 Figure. 3. Daily mass loads of azithromycin (AZI) and clarithromycin (CLA), along with the sum of their 590 metabolites (M), transformation products (TP) and by-products (BP), to the wastewater treatment 591 plant of the city of Zagreb during the one-week sampling interval. 
Table 1. Occurence of target compounds in the wastewater treatment plant of the city of Zagreb.

\begin{tabular}{|c|c|c|c|c|c|c|c|c|c|c|}
\hline \multirow{3}{*}{ Compound } & \multicolumn{5}{|c|}{ Raw wastewater $(n=29)$} & \multicolumn{5}{|c|}{ Secondary effluent $(n=29)$} \\
\hline & \multicolumn{4}{|c|}{ Concentration (ng/L) } & \multirow{2}{*}{ FD (\%) } & \multicolumn{4}{|c|}{ Concentration (ng/L) } & \multirow{2}{*}{ FD (\%) } \\
\hline & Minimum & Maximum & Average \pm SD & Median & & Minimum & Maximum & Average \pm SD & Median & \\
\hline AZI & 269 & 22730 & $5837 \pm 5307$ & 4021 & 100 & 316 & 20178 & $5453 \pm 4816$ & 4451 & 100 \\
\hline DC-AZI & 87 & 7522 & $992 \pm 1485$ & 486 & 100 & 105 & 2370 & $736 \pm 546$ & 623 & 100 \\
\hline $\mathrm{AZI}-\mathrm{PO}_{4}$ & 49 & 1171 & $374 \pm 275$ & 311 & 100 & 73 & 2209 & $618 \pm 518$ & 418 & 100 \\
\hline N-DM-AZI & $<M Q L$ & 74 & $34 \pm 19$ & 32 & 79 & $<M Q L$ & 70 & $38 \pm 20$ & 43 & 76 \\
\hline N'-DM-AZI & $10^{*}$ & 97 & $52 \pm 24$ & 57 & 100 & 13 & 171 & $83 \pm 43$ & 74 & 100 \\
\hline AZI-OX & $<M Q L$ & 83 & $24 \pm 24$ & 12 & 93 & 16 & 479 & $180 \pm 146$ & 116 & 100 \\
\hline$E R Y-\mathrm{H}_{2} \mathrm{O}$ & $10^{*}$ & 129 & $26 \pm 23$ & 21 & 97 & $4.2^{*}$ & 75 & $19 \pm 14$ & 16 & 100 \\
\hline ERY-EE & $3.3^{*}$ & 187 & $22 \pm 38$ & 13 & 100 & $<M Q L$ & 35 & $8.5 \pm 8.0$ & 6.1 & 59 \\
\hline DM-ERY & $<M Q L$ & $<M Q L$ & - & - & 0 & $<M Q L$ & $<M Q L$ & - & - & 0 \\
\hline ERY-IE & $<M Q L$ & $<M Q L$ & - & - & 0 & $<M Q L$ & $<M Q L$ & - & - & 0 \\
\hline ERY-OX & $<M Q L$ & 12 & $7.0^{*} \pm 2.3$ & 6.2 & 21 & 5.5 & 12 & $7.5 \pm 2.5$ & 6.6 & 24 \\
\hline CLA & 111 & 10491 & $828 \pm 1961$ & 389 & 100 & 25 & 2517 & $266 \pm 461$ & 178 & 100 \\
\hline DC-CLA & 13 & 1559 & $142 \pm 328$ & 56 & 100 & 11 & 1570 & $102 \pm 284$ & 44 & 100 \\
\hline DM-CLA & 20 & 170 & $88 \pm 35$ & 100 & 100 & 18 & 153 & $72 \pm 30$ & 72 & 100 \\
\hline ROX & $<M Q L$ & $<M Q L$ & - & - & 0 & $<M Q L$ & $<M Q L$ & - & - & 0 \\
\hline
\end{tabular}

593 FD - Frequency of detection

594 *The concentrations lower than method quantification limit (MQL), but above method detection limit 
595 Table 2. Total mass loads and average removal of target compounds in the wastewater treatment 596 plant of the city of Zagreb during the one-week sampling interval.

\begin{tabular}{lccc}
\hline \multirow{2}{*}{ Compound } & \multicolumn{2}{c}{ Total mass load (g) } & \multirow{2}{*}{ Average removal (\%) } \\
\cline { 2 - 3 } & Raw wastewater & Secondary effluent & \\
\hline AZI & 10249 & 10547 & -3 \\
DC-AZI & 918 & 2400 & -162 \\
AZI-PO $_{4}$ & 1150 & 1238 & -8 \\
N'$^{\prime}-D M-A Z I$ & 69 & 184 & -167 \\
AZI-OX & 20 & 562 & -2659 \\
ERY-H & 98 & 64 & 34 \\
ERY-EE & 115 & 20 & 83 \\
CLA & 1064 & 410 & 61 \\
DC-CLA & 128 & 122 & 5 \\
DM-CLA & 215 & 130 & 40 \\
\hline
\end{tabular}

597 
Table 3. Additional azithromycin (AZI) and clarithromycin (CLA) transformation products (TPS) recently identified in model biotransformation experiments ${ }^{23}$, in raw wastewater (RW) and secondary effluent (SE) from the wastewater treatment plant of the city of Zagreb.

\begin{tabular}{|c|c|c|c|c|c|c|c|c|}
\hline \multirow{3}{*}{ Compound } & \multirow{3}{*}{$\begin{array}{c}\text { ELEMENTAL } \\
\text { COMPOSITION } \\
/[\mathrm{M}+\mathrm{H}]\end{array}$} & \multirow{3}{*}{$\begin{array}{c}m / z \\
\text { (theoretical) }\end{array}$} & \multicolumn{3}{|c|}{ QTOF $^{1}$} & \multicolumn{3}{|c|}{$\mathrm{QqQ}^{2}$} \\
\hline & & & \multirow{2}{*}{$\begin{array}{l}\text { Retention } \\
\text { time } \\
(\min )\end{array}$} & \multirow[t]{2}{*}{$\begin{array}{c}m / z \\
\text { (experimental) }\end{array}$} & \multirow[t]{2}{*}{$\begin{array}{l}\text { Difference } \\
\text { (mDa) }\end{array}$} & \multirow{2}{*}{$\begin{array}{l}2 \text { specific } \\
\text { MRM } \\
\text { transitions }\end{array}$} & \multicolumn{2}{|c|}{$\begin{array}{c}\text { Detection } \\
\text { frequency } \\
(\%)\end{array}$} \\
\hline & & & & & & & RW & SE \\
\hline AZI TP 394 & $\mathrm{C}_{19} \mathrm{H}_{40} \mathrm{NO}_{7}$ & 394.2805 & 2.5 & ND & NA & + & 28 & 10 \\
\hline AZI TP 452 & $\mathrm{C}_{22} \mathrm{H}_{46} \mathrm{NO}_{8}$ & 452.3223 & 2.6 & 452.3225 & +0.2 & + & 0 & 38 \\
\hline AZI TP 376a & $\mathrm{C}_{19} \mathrm{H}_{38} \mathrm{NO}_{6}$ & 376.2699 & 2.6 & 376.2685 & -1.4 & + & 28 & 100 \\
\hline AZI TP 376b & $\mathrm{C}_{19} \mathrm{H}_{38} \mathrm{NO}_{6}$ & 376.2699 & 2.7 & 376.2684 & -1.5 & + & 24 & 97 \\
\hline AZI TP 392 & $\mathrm{C}_{19} \mathrm{H}_{38} \mathrm{NO}_{7}$ & 392.2648 & 2.8 & ND & NA & + & 0 & 14 \\
\hline AZI TP 374a & $\mathrm{C}_{19} \mathrm{H}_{36} \mathrm{NO}_{6}$ & 374.2543 & 2.8 & 374.2532 & -1.1 & + & 0 & 100 \\
\hline AZI TP 374b & $\mathrm{C}_{19} \mathrm{H}_{36} \mathrm{NO}_{6}$ & 374.2543 & 2.9 & 374.2533 & -1.0 & + & 41 & 100 \\
\hline AZI TP 374c & $\mathrm{C}_{19} \mathrm{H}_{36} \mathrm{NO}_{6}$ & 374.2543 & 3.0 & 374.2533 & -1.0 & + & 69 & 100 \\
\hline AZI TP 450 & $\mathrm{C}_{22} \mathrm{H}_{44} \mathrm{NO}_{8}$ & 450.3067 & 3.0 & ND & NA & + & 3 & 7 \\
\hline AZI TP 358 & $\mathrm{C}_{19} \mathrm{H}_{36} \mathrm{NO}_{5}$ & 358.2593 & 3.3 & ND & NA & + & 52 & 86 \\
\hline AZI TP 356 & $\mathrm{C}_{19} \mathrm{H}_{34} \mathrm{NO}_{5}$ & 356.2434 & 3.6 & ND & NA & + & 0 & 52 \\
\hline AZI TP 767 & $\mathrm{C}_{38} \mathrm{H}_{75} \mathrm{~N}_{2} \mathrm{O}_{13}$ & 767.5269 & 3.7 & ND & NA & + & 79 & 79 \\
\hline AZI TP 610 & $\mathrm{C}_{30} \mathrm{H}_{60} \mathrm{NO}_{11}$ & 610.4166 & 4.3 & 610.4172 & +0.6 & + & 28 & 100 \\
\hline AZI TP 608 & $\mathrm{C}_{30} \mathrm{H}_{58} \mathrm{NO}_{11}$ & 608.4010 & 4.6 & ND & NA & + & 7 & 34 \\
\hline AZI TP 592 & $\mathrm{C}_{30} \mathrm{H}_{58} \mathrm{NO}_{10}$ & 592.4061 & 5.6 & 592.4046 & -1.5 & + & 97 & 100 \\
\hline CLA TP 766 & $\mathrm{C}_{38} \mathrm{H}_{72} \mathrm{NO}_{14}$ & 766.4953 & 4.9 & ND & NA & + & 34 & 69 \\
\hline CLA TP $764 a^{3}$ & $\mathrm{C}_{38} \mathrm{H}_{70} \mathrm{NO}_{14}$ & 764.4796 & 5.2 & 764.4831 & +3.5 & + & 100 & 100 \\
\hline CLA TP $828^{4}$ & $\mathrm{C}_{38} \mathrm{H}_{71} \mathrm{NO}_{16} \mathrm{P}$ & 828.4510 & 5.9 & 828.4525 & +1.5 & + & 97 & 100 \\
\hline CLA TP 764b5 & $\mathrm{C}_{38} \mathrm{H}_{70} \mathrm{NO}_{14}$ & 764.4796 & 6.9 & ND & NA & + & 100 & 100 \\
\hline
\end{tabular}

$601{ }^{1}$ QToF data for AZI TPs AND CLA TPs comprise the data obtained for SE sample collected on $31^{\text {st }}$ May 2017 and

$60210^{\text {th }}$ April 2017, respectively; ${ }^{2}$ Confirmation obtained in at least one sample by MRM analysis using QqQ MS;

$603{ }^{3} \mathrm{CLA} 764 \mathrm{a}=\mathrm{CLA}-\mathrm{OH} ;{ }^{4} \mathrm{CLA} 828=\mathrm{CLA}-\mathrm{PO}_{4} ;{ }^{5} \mathrm{CLA} 764 \mathrm{~b}=\mathrm{CLA}-\mathrm{N}$-oxide; QToF - qudrupole time-of-flight mass

604 spectrometer; $\mathrm{QqQ}$ - triple quadrupole mass spectrometer; ND - not detected 